Annales Geophysicae (2002) 20: 161-174 (C) European Geophysical Society 2002

\title{
Ionospheric cusp flows pulsed by solar wind Alfvén waves
}

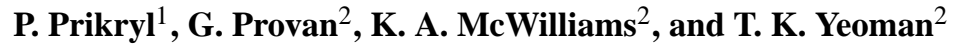 \\ ${ }^{1}$ Communications Research Centre, Ottawa, Ontario K2H 8S2, Canada \\ ${ }^{2}$ Department of Physics and Astronomy, University of Leicester, UK
}

Received: 7 February 2001 - Revised: 24 August 2001 - Accepted: 10 September 2001

\begin{abstract}
Pulsed ionospheric flows (PIFs) in the cusp footprint have been observed by the SuperDARN radars with periods between a few minutes and several tens of minutes. PIFs are believed to be a consequence of the interplanetary magnetic field (IMF) reconnection with the magnetospheric magnetic field on the dayside magnetopause, ionospheric signatures of flux transfer events (FTEs). The quasiperiodic PIFs are correlated with Alfvénic fluctuations observed in the upstream solar wind. It is concluded that on these occasions, the FTEs were driven by Alfvén waves coupling to the dayside magnetosphere. Case studies are presented in which the dawn-dusk component of the Alfvén wave electric field modulates the reconnection rate as evidenced by the radar observations of the ionospheric cusp flows. The arrival of the IMF southward turning at the magnetopause is determined from multipoint solar wind magnetic field and/or plasma measurements, assuming plane phase fronts in solar wind. The cross-correlation lag between the solar wind data and ground magnetograms that were obtained near the cusp footprint exceeded the estimated spacecraft-to-magnetopause propagation time by up to several minutes. The difference can account for and/or exceeds the Alfvén propagation time between the magnetopause and ionosphere. For the case of short period $(<13 \mathrm{~min}$ ) PIFs, the onset times of the flow transients appear to be further delayed by at most a few more minutes after the IMF southward turning arrived at the magnetopause. For the case of long period (30-40 min) PIFs, the observed additional delays were $10-20 \mathrm{~min}$. We interpret the excess delay in terms of an intrinsic time scale for reconnection (Russell et al., 1997) which can be explained by the surface-wave induced magnetic reconnection mechanism (Uberoi et al., 1999). Here, surface waves with wavelengths larger than the thickness of the neutral layer induce a tearingmode instability whose rise time explains the observed delay of the reconnection onset. The compressional fluctuations in solar wind and those generated in the magnetosheath through the interaction between the solar wind Alfvén waves and the
\end{abstract}

Correspondence to: P. Prikryl (paul.prikryl@crc.ca) bow shock were the source of magnetopause surface waves inducing reconnection.

Key words. Interplanetary physics (MHD waves and turbulence) - Magnetospheric physics (magnetosphereionosphere interactions; solar wind-magnetosphere interactions)

\section{Introduction}

Ionospheric dynamics near the cusp footprint attest to processes at the dayside magnetopause and in particular, to pulsed magnetic reconnection (Cowley et al., 1991; Lockwood et al., 1993). A series of quasi-periodic poleward moving auroral forms (PMAFs) at the polar cap boundary (Vorobjev et al., 1975; Sandholt et al., 1990; Øieroset et al., 1997) and pulsed ionospheric cusp plasma flows observed by UHF incoherent scatter (Van Eyken et al., 1984), VHF (Goertz et al., 1985) and HF coherent scatter radars (Pinnock et al., 1995; Provan et al., 1998; Milan et al., 2000) are widely accepted to be ionospheric signatures of pulsed magnetic reconnection. Following Dungey's (1961) introduction of the concept of magnetic reconnection as a steadystate phenomenon in a model of the open magnetosphere, reconnection has become viewed as a time-dependent process, resulting in a non-steady ionospheric convection (Russell, 1972; Russell and McPherron, 1973; Cowley and Lockwood, 1992). While the early observations by ISEE satellites provided evidence for quasi-steady dayside reconnection (Paschmann et al., 1979), impulsive reconnection of the magnetosheath and magnetospheric fields is regarded as a primary mechanism for magnetic flux transfer from the solar wind to the magnetosphere (Russell and Elphic, 1978, 1979). Episodes of such flux transfer, referred to as flux transfer events (FTEs), occur with separation times between successive FTEs, ranging from a few minutes to several tens of minutes (Lockwood et al., 1989; Lockwood and Wild, 1993; Kuo et al., 1995, McWilliams et al., 2000). Search- 


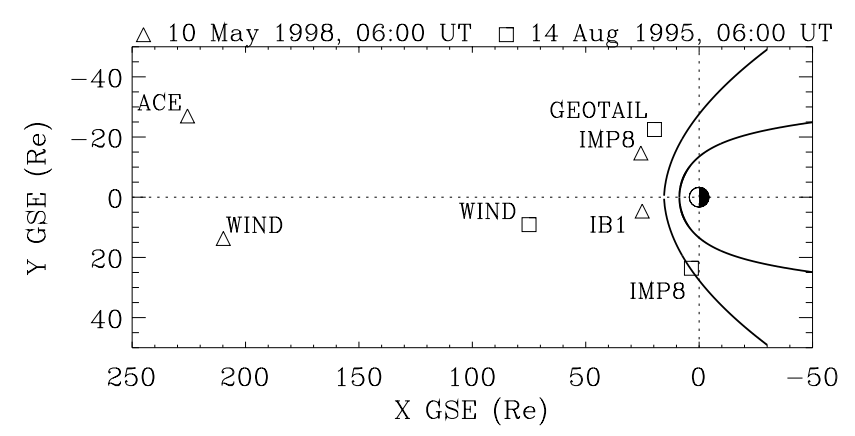

Fig. 1. The ISTP spacecraft positions in GSE coordinates.

ing for the cause of the pulsed nature of reconnection, Lockwood and Wild (1993) suggested that quasi-periodic FTEs could arise from the IMF $B_{Z}$ fluctuations; Le et al. (1993) argued in favor of spontaneously occurring FTEs, while Kuo et al. (1995) and Russell et al. (1997) concluded that the quasi-periodic occurrence of FTEs is controlled by the magnetopause or magnetosphere. Some evidence of solar wind/magnetosheath magnetohydrodynamic (MHD) waves modulating the reconnection rate (as inferred from ionospheric cusp flows observed by SuperDARN) has been found (Prikryl et al., 1998, 1999).

Solar wind plasma is a highly structured and turbulent medium (Tu and Marsch, 1995), supporting a variety of MHD modes. Alfvén waves are commonly observed (Belcher and Davis, 1971), particularly in high-velocity solar wind streams. The Alfvénic fluctuations are often mixed with incompressible convective structures and nonpropagating compressible fluctuations (Tu and Marsch, 1995 and references therein). The latter fluctuations tend to show anti-correlation between the magnetic and kinetic (thermal) pressure, suggesting pressure balanced structures. It is believed that superposed on these fluctuations are magnetosonic waves, although no conclusive evidence for pure magnetosonic modes has been found (Tu and Marsch, 1995). However, such modes are expected to be generated in the magnetosheath through the interaction between the solar wind MHD waves and the bow shock (McKenzie and Westphal, 1969, 1970; Lin et al., 1996; Cable and Lin, 1998). These and other studies (e.g. Hassam, 1978; Sibeck et al., 1997, and the references therein) also showed that solar wind Alfvén waves are transmitted into the magnetosheath. In a recent survey of magnetosheath MHD waves, Sibeck et al. (2000) confirmed theoretical predictions that most of the magnetosheath fluctuations originate in the solar wind and showed that the anti-sunward propagating Alfvénic fluctuations in the solar wind generate anti-sunward and sunwardpropagating (but not strictly Alfvénic) fluctuations in the magnetosheath. Since the amplitudes of the observed velocity fluctuations were depressed by about a factor of 5 or less, with respect to the predicted amplitudes for Alfvénic fluctuations, and both antiphase density and magnetic field magnitude perturbations were present, Sibeck et al. (2000) attributed these fluctuations to slow mode waves.
Previously, interplanetary Alfvén wave trains were identified as a source of high intensity, long duration, continuous auroral activity events (Tsurutani and Gonzalez, 1987). Saunders et al. (1992) studied a response of the dayside ionospheric plasma flow (inferred from the ground magnetic field perturbations) to long-period IMF oscillations. Here, we use the solar wind, HF radar and ground-based magnetometer data to examine the correlations between the Alfvénic fluctuations and pulsed ionospheric flows (PIFs) in the cusp footprint. The observed solar wind-to-ground magnetic field cross-correlation lags are compared with estimated propagation times between the spacecraft and the subsolar magnetopause and with the onset of the ionospheric signatures of FTEs observed by the radar.

\section{Instruments and techniques}

The CUTLASS bistatic radar system (with stations in Finland and Iceland) is part of the extended international network of HF radars called SuperDARN (Super Dual Auroral Radar Network) (Greenwald et al., 1995). Each radar is a frequency-agile $(8-20 \mathrm{MHz})$ radar forming 16 beams of azimuthal separation of $3.24^{\circ}$, each gated into 75 range bins, that are $45 \mathrm{~km}$ long in standard operations when the dwell time for each beam is $7 \mathrm{~s}$, giving a full scan over $52^{\circ}$ in azimuth usually every $2 \mathrm{~min}$. Several parameters, including the line-of-sight (LOS) Doppler velocity, spectral width and backscatter power from the ionospheric plasma irregularities, are routinely measured. In the standard mode, the velocity that is measured by two radars can be combined to provide convection velocity perpendicular to the magnetic field. In addition to the standard scan mode, the data discussed here were obtained by the Finland radar operating in a non-standard, high time resolution (HTR) mode. In these modes, instead of the usual anti-clockwise sweep through the beams, the radar samples between 1 and 3 selected beams more frequently than the others in the sequences, e.g. 5,12 , $5,12,5,12 \ldots$ or $0,5,2,5,4,5 \ldots$ With a dwell time of $7 \mathrm{~s}$ for each beam, this results in a time resolution between 7 and $21 \mathrm{~s}$ for the HTR beams.

Ground-based magnetometer data from the IMAGE array (Viljanen and Häkkinen, 1997) are used to support the SuperDARN data. The International Solar-Terrestrial Physics (ISTP)/Global Geospace Science (GGS) mission includes the WIND spacecraft (Ogilvie and Parks, 1996), with instruments that include the Magnetic Fields Investigation (MFI) and 3-D Plasma (3DP) instrument. GEOTAIL instruments sample the magnetic field (MGF) (Kokubun et al., 1994), the electric fields (Tsuruda et al., 1994) and the plasma parameters (LEP) (Mukai et al., 1994). Additional data from the solar wind and magnetosheath obtained by ACE (Smith et al., 1999), INTERBALL 1 (Klimov et al., 1997) and IMP-8 (King, 1982) are used to examine the spatial coherence of the solar wind structure and to measure the propagation delays between the spacecraft and the ionosphere. 
Table 1. The inter-spacecraft cross-correlation and lag for the time series of the IMF clock angle, $B_{T}$ or $P_{D Y N}$

\begin{tabular}{|c|c|c|c|}
\hline $\begin{array}{l}\text { Spacecraft } \\
\text { pair }\end{array}$ & $\begin{array}{l}\text { Cross-correlation } \\
\text { lag (min) }\end{array}$ & coefficient, & $\begin{array}{l}\text { average lag } \\
(\mathrm{min})\end{array}$ \\
\hline \multirow[t]{2}{*}{10 May 1998} & 04:30-08:30 UT & & \\
\hline & IMF clock angle & $B_{T}$ & \\
\hline WI-I8 & $0.77,+47$ & $0.48,+46$ & 46.5 \\
\hline AC-I8 & $0.77,+37$ & $0.32,+40$ & 38.5 \\
\hline WI-AC & $0.74,+9$ & $0.43,+8$ & 8.5 \\
\hline WI-IB1 & $0.76,+42$ & $0.77,+42$ & 42.0 \\
\hline IB1-I8 & $0.93,+2$ & $0.89,+2$ & 2.0 \\
\hline AC-IB1 & $0.83,+36$ & $0.79,+35$ & 35.5 \\
\hline \multirow[t]{2}{*}{14 Aug. 1995} & 06:00-08:30 UT & & \\
\hline & IMF clock angle & $P_{D Y N}$ & \\
\hline WI-I8 & $0.83,+13.0$ & $0.26,+12.8$ & 12.9 \\
\hline WI-GE & $0.76,+10.3$ & $0.39,+9.3$ & 9.8 \\
\hline GE-I8 & $0.75,+3.0$ & $0.33,+2.8$ & 2.9 \\
\hline
\end{tabular}

\section{Observations}

It is well-known that the magnetic reconnection rate at the magnetopause subsolar point increases when the IMF turns southward (antiparallel merging) (Rijnbeek et al., 1984, Berchem and Russell, 1984). The newly-opened field lines are subject to a curvature force (magnetic tension). As they are straightened and dragged anti-sunward by the solar wind, the ionospheric plasma at the cusp footprint moves with them, resulting in enhanced flows that can be observed by the SuperDARN radars (Pinnock et al., 1995). If the IMF fluctuates ( $B_{Z}$ component, in particular), so does the reconnection rate and the ionospheric flow in the cusp footprint. If the IMF fluctuations are due to Alfvén waves, one can expect a series of quasi-periodic reconnection pulses, evidenced by radar observations of PIFs. The IMF $B_{Y}$ fluctuations control the cusp (DPY) currents (Stauning et al., 1995) that are associated with poleward progressing ionospheric flows for the IMF $B_{Z}<0$. This is demonstrated for long (30-40 min) period Alfvén waves observed in the solar wind on 10 May 1998 (event 1). Another case study (event 2) shows evidence of PIFs driven by short (a few minutes) period Alfvén waves. Figure 1 shows the positions of the ISTP spacecraft for these two events.

\subsection{Event 1: 10 May 1998}

At 06:00 UT, WIND was located at $\left(209.8,13.7,29.2 R_{E}\right)$, IMP-8 was at $\left(25.6,-14.7,14.5 R_{E}\right)$, ACE at $(225.6,-27.0$, $\left.-19.7 R_{E}\right)$ and INTERBALL 1 at $\left(25.1,4.6,3.8 R_{E}\right)$ in GSE coordinates (Fig. 1). At these widely separated locations (WIND at $201.2 R_{E}$, IMP-8 at $21.8 R_{E}$, ACE at 217.0 $R_{E}$, and INTERBALL 1 at $14.8 R_{E}$ from the magnetopause, respectively), all four spacecraft observed large amplitude Alfvénic fluctuations having similar wave forms for many hours. Figure 2 shows the IMF and plasma data from
WIND demonstrating the presence of Alfvén waves in the solar wind: the corresponding components of the IMF and ion velocity fluctuations are highly correlated (correlation coefficients and scatter plots are shown), while the magnitude of the IMF, ion velocity and density remained relatively constant or fluctuated only with smaller amplitudes (Fig. 2). For sunward oriented background IMF $\left(B_{X}>0\right)$, the positive correlations indicate anti-sunward propagating Alfvén waves (Belcher and Davis, 1971) convected at the solar wind speed of about $500 \mathrm{~km} / \mathrm{s}$. In addition, we compared the predicted Alfvénic velocity fluctuations obtained from the Walén relation $\Delta \boldsymbol{V}= \pm \Delta \boldsymbol{B} /\left(\mu_{0} \rho\right)^{1 / 2}$, where $\rho, \boldsymbol{V}$ and $\boldsymbol{B}$ are the plasma mass density, ion velocity and magnetic field, respectively, with the observed fluctuations in $\boldsymbol{B}$. Following Sibeck et al. (1997), we assumed that alpha particles constitute $10 \%$ of the solar wind number density. In addition, the waveforms and amplitudes of the predicted (not shown) and observed velocity fluctuations are very similar, thus confirming the Alfvénicity of the solar wind fluctuations during this time. As already mentioned above, in addition to being transmitted across the bow shock, the solar wind Alfvén waves generate other MHD modes in the magnetosheath. There was no spacecraft in the magnetosheath during this event, but GOES satellites on the geosynchronous orbit observed quasi-periodic compressions of the magnetospheric magnetic field (not shown) in the dusk/evening sector, indicating the presence of pressure pulses in the magnetosheath. The inter-spacecraft cross-correlation coefficients and lags that are computed using the IMF clock angle $\left(\arctan \left(B_{Y} / B_{Z}\right)\right)$ (Fig. 3a) and the magnitude $B_{T}$ measurements from pairs of spacecraft are listed in Table 1.

\subsubsection{Estimate of the spacecraft-magnetopause time lag}

When estimating propagation delays between a single spacecraft and the subsolar magnetopause, a standard approach (Lester et al., 1993) is to assume that the solar wind disturbance "phase front" is aligned with the mean IMF. Figure 3a shows the IMP-8 IMF $B_{Y}$ and $B_{Z}$ components and clock angle (solid lines). The superposed broken lines in the top two panels (Fig. 3a) show smoothed values (2-h smoothing window is used) of the angle $\varphi_{B}$ between the positive $X$ (EarthSun) axis and the projection of the magnetic field vector $\boldsymbol{B}$ on the $X Y$ plane, and the $\boldsymbol{B}$ inclination $\theta_{B}$ to the $X Y$ plane. For a "phase front" at an angle with respect to the Sun-Earth line between $55^{\circ}$ and $80^{\circ}$ (this range is slightly different for each spacecraft) and the solar wind speed $\left(V_{S W}\right)$ of 500 $\pm 20 \mathrm{~km} / \mathrm{s}$, the estimated mean propagation delays between the spacecraft and the subsolar magnetopause (Lester et al., $1993)$ are $50 \pm 3 \mathrm{~min}, 47 \pm 3 \mathrm{~min}, 7 \pm 1 \mathrm{~min}$ and $5 \pm 1 \mathrm{~min}$, for WIND, ACE, INTERBALL 1 and IMP 8, respectively. As discussed by Lester et al. (1993), for propagation in the magnetosheath, we adopt the magnetogas dynamic Spreiter and Stahara (1980) model for the interaction of the solar wind and magnetosphere for a given solar wind speed and dynamic pressure $(2 \mathrm{nPa})$.

In reality, the mean IMF vector may not lie in the plane 


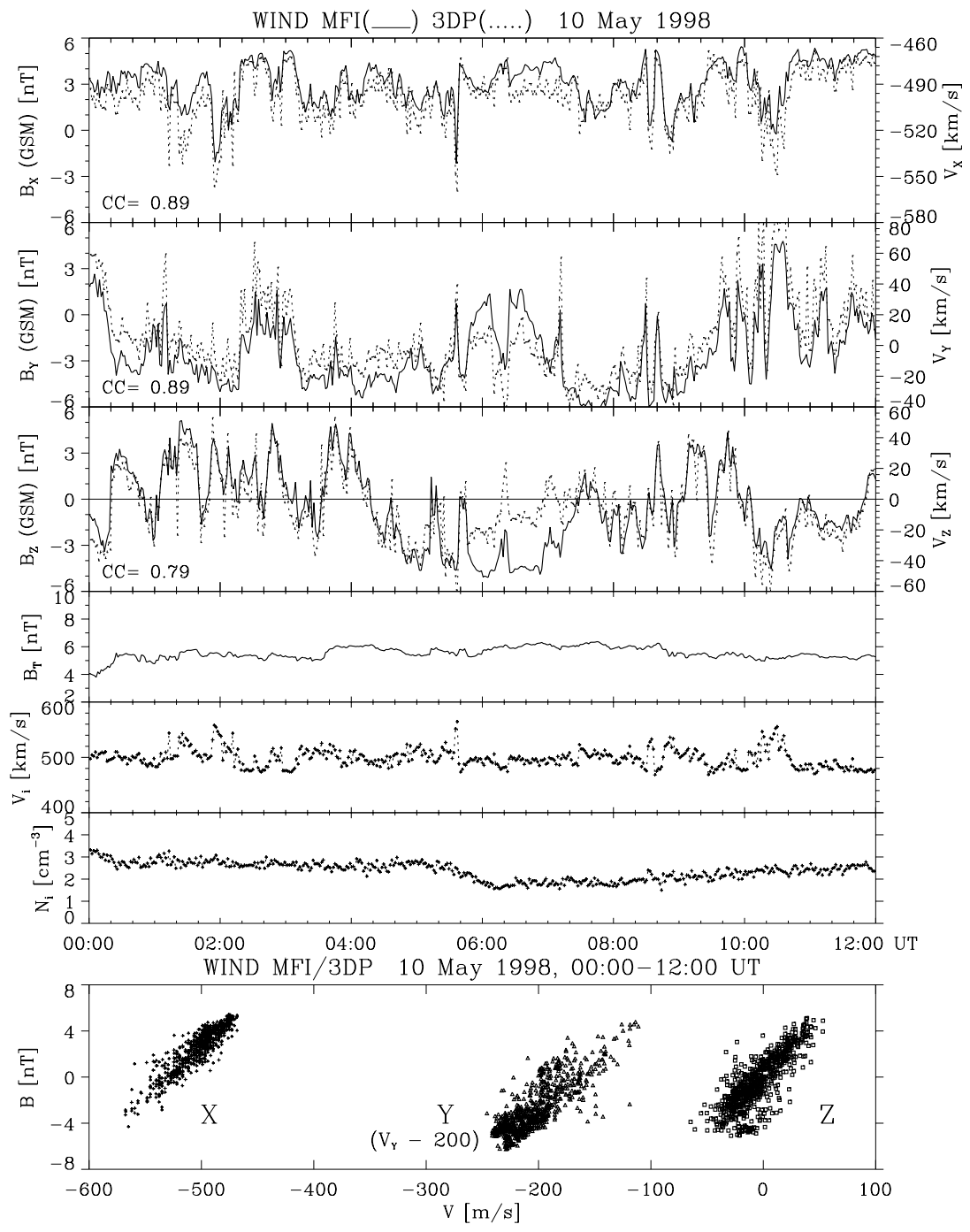

Fig. 2. Alfvénic fluctuations in the solar wind observed by WIND spacecraft on 10 May 1998. The coefficients of correlation (CC) between the corresponding components of the IMF (solid line) and ion velocity (dotted line) and scatter plots (bottom) are shown.

of the phase front (Richardson and Paularena, 1998). With multiple spacecraft monitoring the solar wind, we can compute (Nishitani et al., 1999) the orientation of the phase fronts (assuming plane wave propagation) by using the correlation lags between pairs of spacecraft. For each pair, we take an average of the time lags obtained for the IMF clock angle and magnitude $B_{T}$ (Table 1). For the observed solar wind velocity vector $\boldsymbol{V}$ and the average correlation lag $\tau$ measured by a pair of spacecraft separated by a vector $\boldsymbol{d}$, one can find the orientation angles $\varphi_{n}$ and $\theta_{n}$ of the normal $\boldsymbol{k}_{n}$ to the phase front passing the spacecraft by solving the vector equation.

$(\mathbf{d}-\tau \mathbf{V}) \bullet \mathbf{k}_{n}=0$

which can be written in the form (Nishitani et al., 1999):

$$
\begin{aligned}
& \left(X_{2}-X_{1}-V_{X} \tau\right) \cos \varphi_{n}+\left(Y_{2}-Y_{1}-V_{y} \tau\right) \sin \varphi_{n} \\
& +\left(Z_{2}-Z_{1}-V_{z} \tau\right) \tan \theta_{n}=0
\end{aligned}
$$

where $\mathrm{t}$ is the time lag between phase fronts convected at velocity $\boldsymbol{V} \equiv\left(V_{x} V_{y} V_{z}\right)$ passing two spacecraft located at $\left(X_{1}, Y_{1}, Z_{1}\right)$ and $\left(X_{2}, Y_{2}, Z_{2}\right)$ in GSE coordinates. For simplicity, we take $V_{y}=V_{z}=0$ (approximately true, on average; Fig. 2) and use the mean correlation lag for $\tau$. Figure 4 shows the possible orientations of the solar wind front for two spacecraft pairs. By varying $\varphi_{n}$ from $-90^{\circ}$ to $+90^{\circ}$, the corresponding $\theta_{n}$ is calculated. The shaded rectangle represents a subrange of values, $\varphi_{n}$ and $\theta_{n}$, that satisfy the equation for a given range of $V_{S W}$. Other combinations of spacecraft pairs give similar results. A range of possible angles, $\varphi_{n}$ and $\theta_{n}$, is obtained and the corresponding values of the propagation delay between the spacecraft and the subsolar magnetopause are computed.

This is the principal method that we used for event 2 when solar wind data were available from only three spacecraft. Since there were four spacecraft monitoring the solar wind during event 1 , the propagation delays can be obtained 


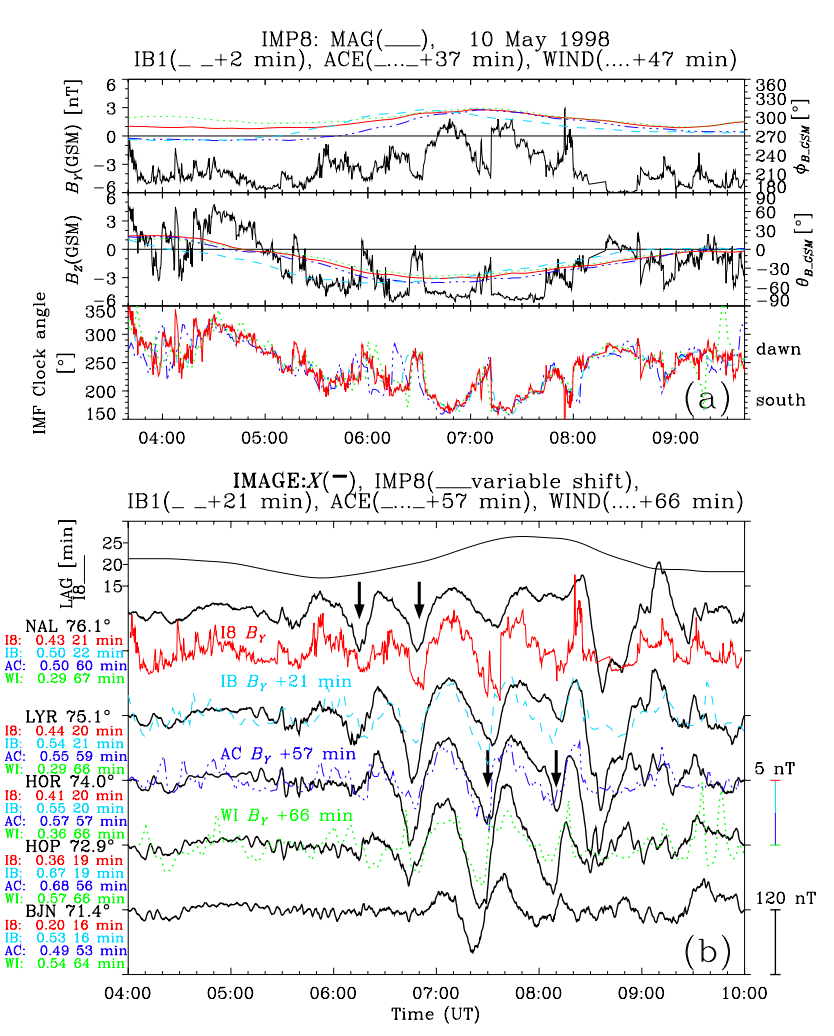

Fig. 3. (a) The IMF $B_{Y}, B_{Z}$ (IMP-8), clock angle and the mean IMF orientation angles $\varphi_{B}$ and $\theta_{B}$. The INTERBALL (light blue), ACE (dark blue) and WIND (green) time series are shifted relative to IMP-8 (black or red). (b) The detrended $X$ component of the ground magnetic field (black heavy lines) measured by the IMAGE (Svalbard) magnetometer array. The curve at the top shows the variable lag obtained from the correlation between the IMP-8 IMF $B_{Y}$ and NAL ground magnetic field $X$ component using an advancing 1-h window. Detrended and time shifted IMF $B_{Y}$ time series measured by IMP-8 (variable shift), INTERBALL 1, ACE and WIND are superposed. The maximum correlation coefficients and corresponding average lags are shown on the left. The arrows indicate the intensifications of the westward DPY current.

from cross-correlations using a more direct but similar approach. Cross-correlation lags for spacecraft pairs are all expressed relative to one of the four spacecraft and a system of three linear equations where the components of the normal of the phase front are at first, unknown and are then solved (Russell et al., 2000; their Eq. 5). Using the average cross-correlation lags (Table 1) and the solar wind speed $500 \pm 20 \mathrm{~km} / \mathrm{s}$, we find a range of normal directions. Assuming a plane "phase front", we then estimate that the propagation delays between the spacecraft and the subsolar magnetopause are 50.2 $\pm 2.0 \mathrm{~min}$ (WIND), $43.6 \pm 1.8 \mathrm{~min}$ (ACE), $7.6 \pm 0.3 \mathrm{~min}$ (INTERBALL 1), and $5.6 \pm 0.2 \mathrm{~min}$ (IMP-8). Although other estimates are discussed in this section, we consider the latter to be the most reliable in our case and use these values in further discussion. These estimates differ from those that are based on the assumption that the mean IMF vector lies in the plane of constant phase by at most a few minutes.

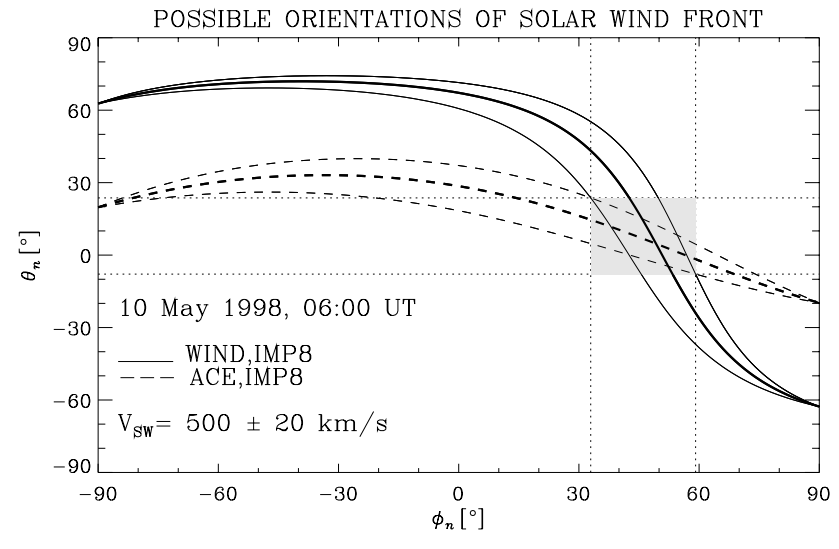

Fig. 4. Possible orientations of solar wind front. Varying $\varphi_{n}$ from $-90^{\circ}$ to $+90^{\circ}$ corresponding angles $\theta_{n}$ are computed for two spacecraft pairs. The shaded rectangle gives a subrange of values for $\varphi_{n}$ and $\theta_{n}$ that satisfy Eq. (2) for a given range of $V_{S W}$ and the observed propagation lags between the spacecraft.

Another way to determine the orientation of the solar wind "phase front" is to examine sharp changes in the IMF. Using the minimum variance method (Sonnerup and Cahill, 1967; Siscoe et al., 1968), normals of solar wind discontinuities can be determined. We identified 7 sharp changes in the 15s IMF data from IMP-8 between 05:00 and 08:00 UT for which the normal directions $\varphi_{n}$ and $\theta_{n}$ are well determined to be $34 \pm 6^{\circ}$ and $11 \pm 20^{\circ}$, respectively. The intermediateto-minimum variance ratios were $\gg 1$ using the Siscoe et al. (1968) algorithm. Similar mean normal directions are found from WIND and ACE IMF data. In agreement with the results discussed above, the estimated propagation times from WIND, ACE and IMP-8 to the subsolar magnetopause for the solar wind speed of $500 \pm 20 \mathrm{~km} / \mathrm{s}$ are $49 \pm 3,44 \pm 3$, and $5 \pm 2 \mathrm{~min}$. This method was not used with the INTERBALL 1 data which were available to us at a lower time resolution (2 min).

\subsubsection{Comparison with the observed cross-correlation lags}

Figure $3 b$ shows the time series of the ground magnetic field $X$ component perturbations due to DPY currents measured by the IMAGE (Svalbard) magnetometer array and correlated with the IMF $B_{Y}$ measured by IMP-8, INTERBALL 1, ACE and WIND. The time series are detrended by subtracting a 1-h running average. Four major enhancements of the DPY current are indicated by arrows. The correlation lags and corresponding correlation coefficients are shown for each spacecraft and 5 IMAGE magnetometers (Fig. 3b). The average time lags range from 64-67 $\mathrm{min}$ (WIND), 53-60 min (ACE), 16-21 $\mathrm{min}$ (INTERBALL 1), and 16-22 min (IMP8) (see also Table 2). These correlation lags are 8-17 min longer than the estimated spacecraft-magnetopause propagation time estimates discussed above.

The above correlation lags only give average delays of the ionospheric response to the solar wind driver. At highlatitudes (NAL), the delays were quite variable over the 6- 
SuperDARN FINLAND: vel 10 May $1998^{(130)}$

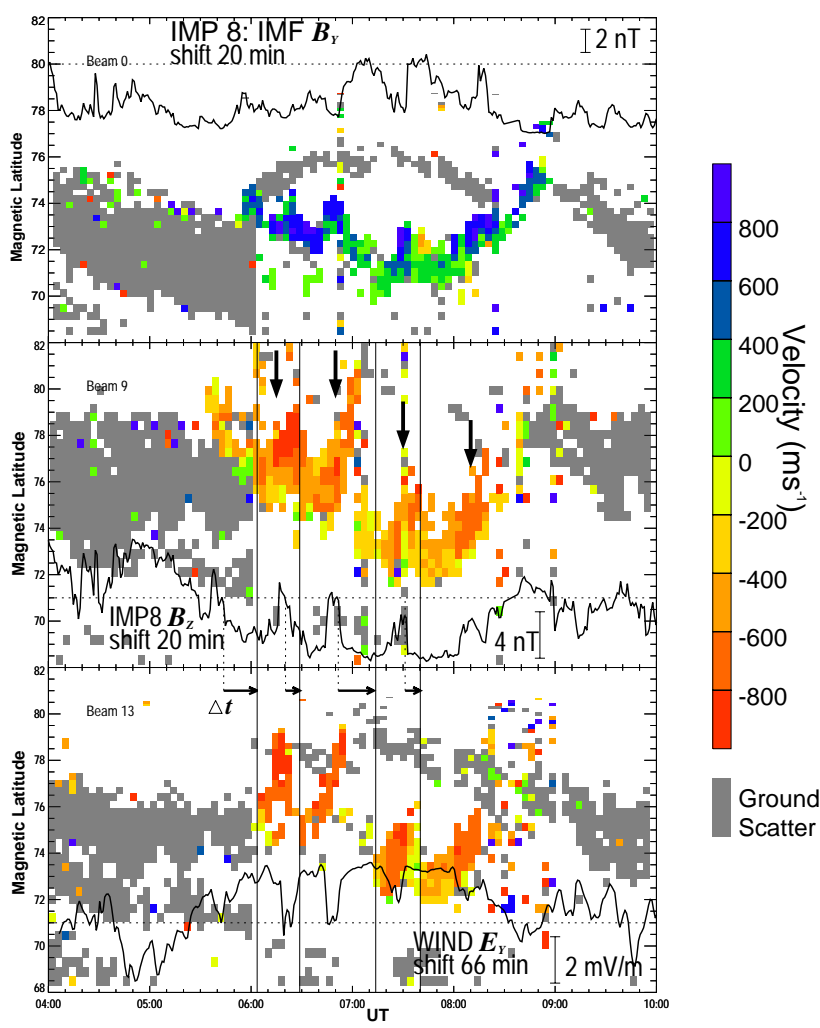

Fig. 5. The Finland radar (beams 0, 9, and 13) color-coded line-of-sight velocity showing quasi-periodic poleward progressing flow bursts (PIFs) associated with the DPY current intensifications (downward arrows from Fig. 3b). Time series of the IMP-8 IMF $B_{Y}, B_{Z}$ and solar wind dawn-dusk electric field $E_{Y}$ that are shifted by the observed spacecraft-to-ground mean lag are superposed. The solid vertical lines show the onset times of PIFs (assumed to be signatures of the onset of reconnection at the magnetopause) and the dotted vertical lines indicate the IMF southward turning. The length of the horizontal arrow indicates the inferred delay $(\Delta t)$ of the reconnection onset after the IMF southward turning at the magnetopause.

$\mathrm{h}$ period shown in Fig. 3. To examine the delay variability, correlation lags were computed for NAL $X$ and IMP-8 $B_{Y}$ time series using a 1-h window that was shifted in 30 min steps. The resulting time series of lags that was interpolated to match the magnetometer sampling rate and then smoothed is shown in Fig. $3 b$ (top thin solid line). The time lags for NAL range between 17 and $27 \mathrm{~min}$, but are fairly constant (not shown) for BJN or HOP. The variable time lags obtained from the correlation analysis are used to shift the IMP-8 IMF time series that is shown in Fig. 3b. After the adjustment for the variable delay, the IMP- $8 B_{Y}$ trace (plotted just under the NAL time series) matches rather well the long period variation of the ground magnetic field. The lag variation may partly be caused by a variable orientation of the phase front approximately aligned with the mean IMF. However, the main reason is the delayed ionospheric response, i.e. the phase progression with latitude: NAL X leads BJN $\mathrm{X}$ by about $13 \mathrm{~min}$ at $\sim 07: 30 \mathrm{UT}$ when the amplitude maximized at HOP. For the oscillation period of $40 \mathrm{~min}$, this is a phase shift of $\sim 120^{\circ}$ and although the period is very long the latitude dependence of the phase and amplitude resembles an FLR signature that appears to be cut off at highlatitudes because the field line has been opened (Prikryl et al., 1998). The progression of the phase with latitude is crucial for the interpretation of the difference between the observed cross-correlation lags and the estimated propagation times discussed above. It is well-known that the fast mode reaches the low-latitudes (small L-shells) within $\sim 1 \mathrm{~min}$. It couples to shear mode which takes longer time to reach the high-latitudes propagating along the field line (at larger Lshells). The minimum difference between the observed lag and estimated propagation time to magnetopause of $\sim 8 \mathrm{~min}$ for BJN can at least partly be explained by the Alfvén propagation time in the magnetosphere considering the long period (wavelength) of the wave. Similarly, Saunders et al. (1992) found the minimum ionospheric response time to the IMF changes at the magnetopause to be $\sim 5$ min (after subtracting the estimated propagation times in the solar wind, magnetosheath and magnetosphere).

\subsubsection{Radar observations of PIFs}

The long period ground magnetic $X$ component perturbations are due to poleward progressing DPY currents (e.g. Stauning et al., 1995). For the IMF $B_{Y}<0$ and $B_{Z}<0$, the intensifications of the Hall current move poleward and are associated with eastward (electron) flow channels. Figure 5 shows the CUTLASS Finland radar latitude-time-velocity (LTV) plots for beams 0,9 , and 13. The dwell time for each beam was $12 \mathrm{~s}$ and a full scan took 4 min dresulting in a lower than standard time resolution. The LOS velocity is colorcoded with negative velocities indicating motions away from the radar, while grey indicates ground scatter. Superposed are the IMF $B_{Y}$ and $B_{Z}$ from IMP-8 (1 min averages) shifted by 20 min. In addition, superposed in the bottom panel (Fig. 5) is the solar wind dawn-dusk component of the electric field shifted by $66 \mathrm{~min}$. The electric field $\left(E_{Y}=(-\boldsymbol{V} \times \boldsymbol{B})_{Y}\right)$ that is derived from the WIND MFI/3DP data fluctuated quasiperiodically with amplitudes up to $\pm 2 \mathrm{mV} / \mathrm{m}$.

It was only after the ambient IMF and solar wind electric field turned southward and duskward, respectively, that a significant merging occurred at the subsolar point. This is evidenced by long period (30-40 min) PIFs observed in the cusp footprint that is identified by backscatter associated with large spectral widths (not shown) exceeding $400 \mathrm{~m} / \mathrm{s}$ between 05:30 and 08:30 UT. Note that the radar frequency changed at 06:00 UT, resulting in the ground scatter shift at this time. This may have prevented observation of the PIF activity prior to 06:00 UT (only a trace of a flow burst is seen by beam 9 at 05:40 UT). Each consecutive flow burst started at a lower latitude as a consequence of intense magnetic flux erosion, while the ambient IMF remained southward. For east-west oriented flow channels that are tilted with respect to constant 
magnetic latitude, the observed velocities are LOS components of the pulsed northeastward flow in poleward progressing flow channels (Fig. 6). Four major flow channels are associated with poleward progressing enhancements of the westward DPY Hall current detected by the IMAGE magnetometer chain (see heavy arrows). For IMF $B_{Y}<0$, the cusp is displaced to the pre-noon sector (07:00 UT corresponds to about 10:00 MLT for beam 9); thus, we conclude that the radar beams observed within the convection throat are the flows on newly-reconnected field lines since they were dragged anti-sunward and duskward. In terms of ionospheric (DPY) currents, this is a well-known response to fluctuating and predominantly negative IMF $B_{Y}$ (Stauning et al., 1995).

The IMF clock angle is often invoked when discussing the FTE occurrence (e.g. Berchem and Russell, 1984; Neudegg et al., 2000). On 10 May, the PIFs were observed when the mean IMF clock angle was between $180^{\circ}$ and $270^{\circ}$, which is consistent with the statistical survey of magnetopause FTEs (Neudegg et al., 2000; see their Fig. 1). The dawn-dusk component of the solar wind Alfvén wave electric field (Fig. 5; bottom panel) if imposed on the magnetopause along the $X$ line is expected to modulate the reconnection rate. Assuming that the low-latitude edge of the flow burst is the ionospheric signature of the FTE onset at the subsolar magnetopause then the reconnection is delayed after the southward IMF (duskward electric field) at the magnetopause. In Fig. 5, the solid vertical lines indicate the onset times ( $\pm 4 \mathrm{~min})$ of PIFs and the broken vertical lines show times (corrected for propagation delay) of the IMF turnings. The observed PIF delays suggest that the reconnection onset at the subsolar magnetopause is delayed by $10-20 \mathrm{~min}$ from the arrival of the southward IMF $B_{Z}$. This is further discussed in Sect. 4.

For event 1 , we have concentrated on the large-scale, longperiod Alfvénic IMF fluctuations and the ionospheric response. The radar operated at lower than standard temporal resolution, which does not allow one to study PIFs on scales of a few minutes or less. The PIF repetition periods of 30$40 \mathrm{~min}$ are much longer than the radar scan time of $4 \mathrm{~min}$. PIF periods that are 3 to 4 times shorter can be resolved (e.g. Prikryl et al., 1998) when the SuperDARN radars are operated in standard mode ( 2 min scan), but higher temporal resolution is required to resolve PIFs with periods of a few minutes (Provan et al., 1998). In principle, one would expect that solar wind Alfvén waves with periods of a few minutes should similarly modulate the reconnection rate into pulses a few minutes apart, as long as there are significant $E_{Y}$ oscillations transmitted into the magnetosheath. However, in the search for correlations between solar wind Alfvén waves and PIFs similar to those in Fig. 5 but on shorter time scales, the spatial coherence of waves in the solar wind is yet another limiting factor to contend with. While there is a high spatial coherence of long-period solar wind structure observed between the spacecraft on 10 May 1998 (for time scales greater than about half an hour, the corresponding solar wind Alfvén wavelength is greater than about $15 R_{E}$ ), the correlation on short time scales is usually less evident or lacking. The observed solar wind Alfvén wave period of a few minutes cor-

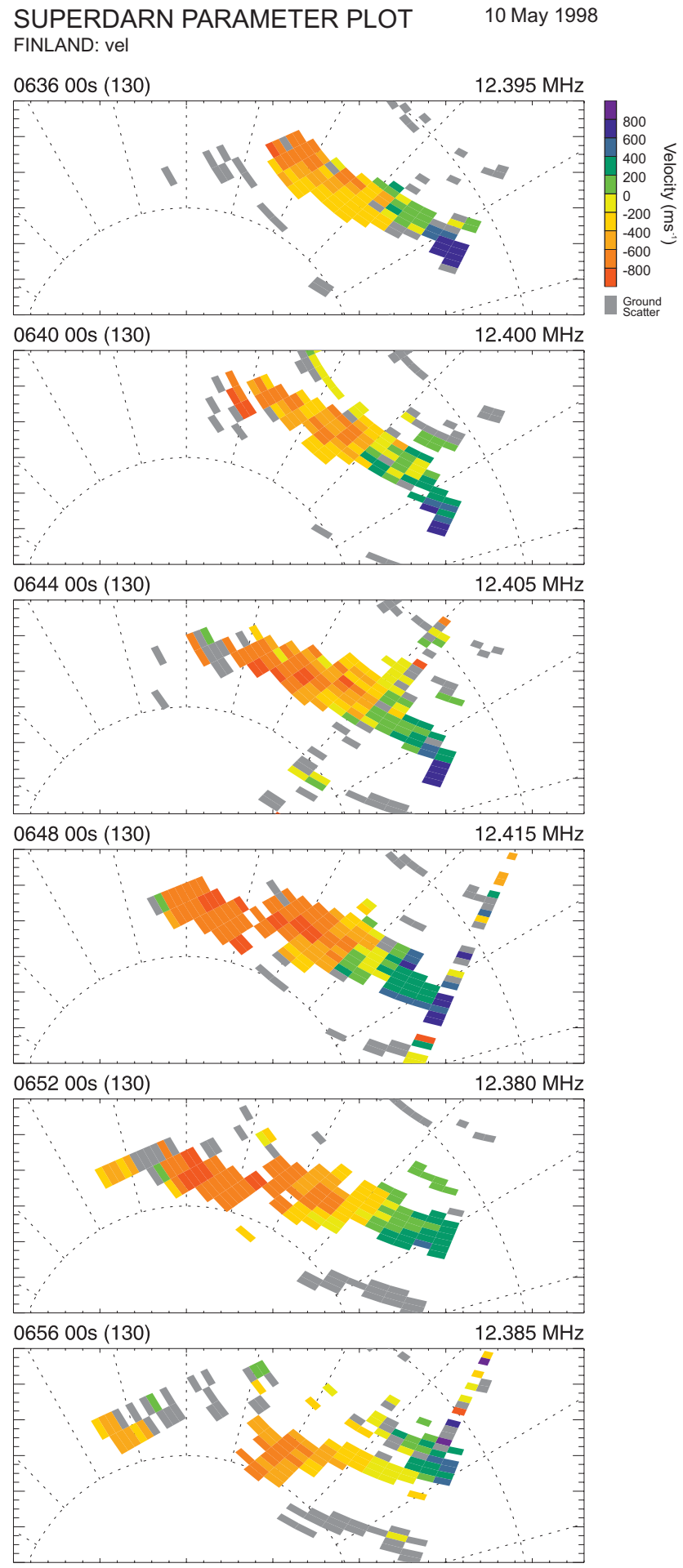

Fig. 6. The Finland radar velocity maps (magnetic local time versus magnetic latitude; 12:00 MLT is to the top) showing a poleward progressing flow channel.

responds to a wavelength of only a few $R_{E}$. Clearly, on such short time scales, it is less likely (but possible) that a certain wave train can be observed by two widely separated spacecraft in the upstream solar wind or that it will actually impinge on the magnetopause at the subsolar point. Further- 


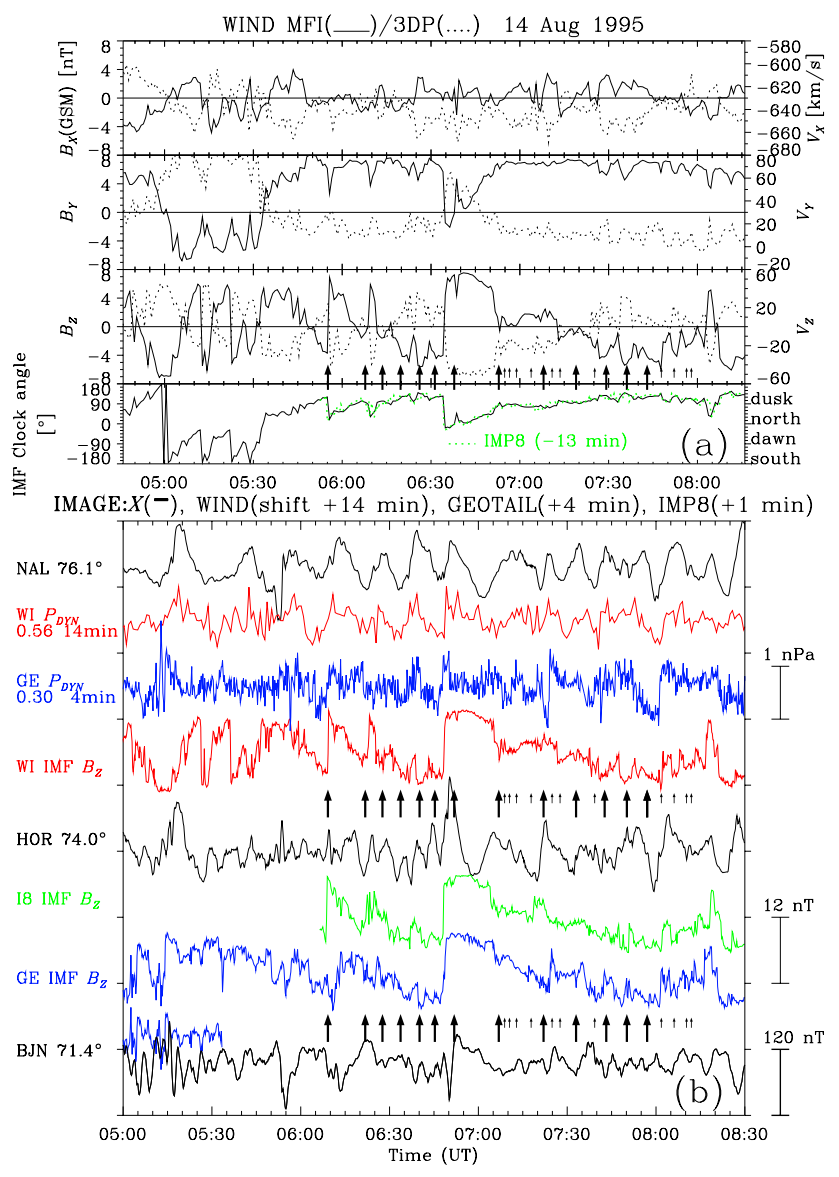

Fig. 7. (a) Alfvénic fluctuations observed in the solar wind magnetic field (solid lines) and ion velocity (black dotted lines) observed by WIND. The bottom panel shows the IMF clock angle for WIND and IMP-8 (green). (b) The detrended $X$ component ground magnetic field (black), measured by the IMAGE (Svalbard) magnetometer, array and the detrended and shifted solar wind dynamic pressure $P_{D Y N}$, measured by WIND (red) and GEOTAIL (blue), are shown (average correlation coefficients and lags are shown on the left). In addition, the time shifted IMF $B_{Z}$ for WIND (red), GEOTAIL (blue), and IMP-8 (green) are superposed. The large and small arrows indicate the onset times of major and minor PIFs, respectively.

\subsection{Event 2: 14 August 1995}

Figure 7a shows the components of the IMF and solar wind ion velocity, and the IMF clock angle observed by WIND. In addition the IMF clock angle measured by IMP-8 is superposed. At 06:00 UT, three spacecraft were located in the solar wind: WIND at $\left(75.0,9.1,-4.1 R_{E}\right.$; GSE) about $64.7 R_{E}$ from the magnetopause (Roelof and Sibeck, 1993), GEOTAIL at $\left(19.7,-22.5,-3.9 R_{E}\right)$ and IMP-8 at (3.4, 23.6, $-16.3 R_{E}$ ) (Fig. 1). All three spacecraft observed a mixture of Alfvénic (the corresponding components of the magnetic field and ion velocity are anticorrelated) and compressional fluctuations. Time shifted solar wind dynamic pressure $\left(P_{D Y N}\right)$ and the IMF $B_{Z}$ time series are superposed in Fig. 7b. The cross-correlation coefficients and interspacecraft lags obtained for pairs of spacecraft using the IMF clock angle and dynamic pressure time series are shown in Table 1. While the overall correlation is high, there are significant differences on time scales of a few minutes (e.g. IMF $B_{Z}$ in Fig. 7b). Unlike event 1 , the IMF $B_{Y}$ was strongly positive for the most part (duskward) when PIFs were observed during event 2 .

\subsubsection{Estimate of the spacecraft-magnetopause time lag}

Similar to event 1 , the orientation of the plane phase fronts are inferred from inter-spacecraft cross-correllation lags (Table 1). For solar wind speed $V_{S W}=640 \pm 20 \mathrm{~km} / \mathrm{s}$ and an average dynamic pressure of $5 \mathrm{nPa}$, the estimated propagation times (Table 2) between each spacecraft and the subsolar magnetopause are $13.1 \pm 0.5 \mathrm{~min}, 3.2 \pm 0.5 \mathrm{~min}$, and $0.3 \pm 0.5 \mathrm{~min}$, for WIND, GEOTAIL, and IMP-8, respectively. In addition, the normal directions of several solar wind discontinuities are determined by using the minimum variance method with high resolution IMF data between 05:50 and 06:40 UT. The mean normal directions are $\varphi_{n}=1 \pm$ $6^{\circ}$ and $\theta_{n}=20 \pm 10^{\circ}$. Assuming that these are planar discontinuities that are convected by solar wind, the estimated propagation times between each spacecraft and the subsolar magnetopause are $13 \pm 3 \mathrm{~min}, 3 \pm 2 \mathrm{~min}$, and $0 \pm 2 \mathrm{~min}$, for WIND, GEOTAIL, and IMP-8, respectively. The propagation time for the WIND is in good agreement with the one obtained by Provan et al. (1998).

\subsubsection{Comparison with the observed cross-correlation lags}

Figure $7 \mathrm{~b}$ shows IMAGE magnetometer data (heavy lines) for NAL, HOR and BJN. The time series are detrended (highpass filtered) by subtracting a 20-min running average to highlight the short-period fluctuations. The ground magnetic $X$ component plots are interspersed with time series of the solar wind dynamic pressure $\mathrm{P}_{D Y N}$ and IMF $B_{Z}$ from WIND, GEOTAIL and IMP-8 (IMP-8 plasma data are not shown). The solar wind time series are shifted using best-fit propagation lags that are further discussed below. The (detrended) dynamic pressure that fluctuated quasi-periodically with periods between 10 and $20 \mathrm{~min}$ is correlated with the gust 1995; see Provan et al., 1998) is further discussed below. 
Table 2. The propagation time (min)

\begin{tabular}{lll}
\hline $\begin{array}{l}\text { Date/ } \\
\text { spacecraft }\end{array}$ & $\begin{array}{l}\text { Estimated } \\
\text { s/c to MP }\end{array}$ & $\begin{array}{l}\text { Observed (min) } \\
\text { s/c to ionosphere }\end{array}$ \\
\hline 10 May 1998 & & IMF $B_{Y}$, IMAGE $X$ \\
IMP-8 & $5.6 \pm 0.2$ & $19 \pm 3$ \\
IB1 & $7.6 \pm 0.3$ & $19 \pm 3$ \\
ACE & $43.6 \pm 1.8$ & $57 \pm 3$ \\
WIND & $50.2 \pm 2.0$ & $65 \pm 2$ \\
& & \\
14 Aug. 1995 & $13.1 \pm 0.5$ & $P_{D Y N}$, NAL $X$ \\
WIND & $14.4 \pm 1.0$ \\
GEOTAIL & $3.2 \pm 0.5$ & $4.0 \pm 1.5$ \\
IMP-8 & $0.3 \pm 0.5$ & $1.5 \pm 2.7$ \\
\hline
\end{tabular}

NAL $X$ component. The GEOTAIL $P_{D Y N}$ time series was smoothed by using a 1-min sliding window prior to the crosscorrelation with NAL $X$. For the time interval of 06:0008:30 UT that is of interest here, mean cross-correlation coefficients and lags are computed for WIND, GEOTAIL and IMP-8 (see Fig. $7 \mathrm{~b}$ and Table 2). The mean lags are used to shift the IMF $B_{Z}$ and $P_{D Y N}$ time series (Fig. 7b). At lower latitudes (HOR and BJN), a mixture of short- and longperiod magnetic field pulsations is observed. However, only some of this can be readily attributed to the solar wind pressure fluctuations. At 05:00-05:30 UT, a burst of a shortperiod (3-5 min) pulsation that is superposed on a long period $(\sim 20 \mathrm{~min})$ oscillation of the ground magnetic $X$ component at HOR and BJN is clearly a response to the solar wind $P_{D Y N}$ pulses, particularly those observed by GEOTAIL. A one-to-one correspondence can also be seen between the HOR/BJN $X$ component and the IMF $B_{Z}$, which are anticorrelated (see the inset in Fig. 7b, lower left, showing a segment of the detrended/hipass-filtered GEOTAIL IMF $B_{Z}$ time series). The NAL was near the convection reversal boundary (CRB) determined from SuperDARN radar data (Provan et al., 1998) and thus near the open/closed field line boundary. The ground magnetic field pulsation at NAL appears to be a signature of magnetopause surface waves driven by solar wind pressure fluctuations. HOR was just equatorward of CRB (Provan et al., 1998), except in the interval 06:40-07:00 UT, when CRB briefly moved south of HOR as a result of intense flux erosion due to pulsed reconnection. The 5-7 min pulsation between 06:20 and 07:00 UT is closely associated with PIFs (indicated by arrows that are discussed below) and southward turnings of the IMF. After 07:00 UT, the IMF fluctuations and PIFs were more irregular (less monochromatic) but correlated, as discussed in the next section. In addition, as already noted above, there is a correlation between the IMF $B_{Z}, P_{D Y N}$, and HOR/BJN $X$, particularly for GEOTAIL. The dynamic pressure fluctuations were most likely a source of surface waves on the magnetopause.

The mean correlation lag between the solar wind dynamic pressure $\left(P_{D Y N}\right)$ and ground magnetic field ( $X$ component at NAL) exceeded the estimated spacecraft-to-magnetopause propagation time by $\sim 1 \mathrm{~min}$ (Table 2 ), which is consistent with fast mode propagation. The correlation between the IMF $B_{Y}$ and DPY currents (ground magnetic field $X$ component) was not evident. Unlike the radar, the ground magnetometers integrate the contributions from ionospheric currents over a large area overhead and are not expected to unambiguously resolve small-scale and dynamic FTE signatures. Furthermore, beam 5 is significantly westward of the IMAGE (Svalbard) magnetometer array, so a direct comparison with the radar data may not necessarily be meaningful unless the currents are sufficiently extended in longitude. The HOR magnetometer that was located near CRB (before 06:40 and after 07:00 UT) sensed the return currents equatorward of CRB and observed a magnetic pulsation that was similar to PIFs, particularly those between 06:00 and 07:00 UT.

\subsubsection{Radar observations of PIFs}

On 14 August 1995, CUTLASS Finland radar was operated in a non-standard scan mode, sampling alternately on beams 5 and 12. This resulted in a $14 \mathrm{~s}$ temporal resolution for each beam, with a $45 \mathrm{~km}$ resolution in range. Figure 8 shows the LOS velocity RTV plot (beam 5), revealing the ionospheric signatures of reconnection (PIFs) that were observed by the Finland radar (see also Provan et al., 1998). The transients appear to be moving away, as expected, from the radar of the newly-open flux which is dragged anti-sunward with the solar wind flow, while driving fast plasma flow in the zonal direction under the curvature ("magnetic tension") force. The approximate start times of the transients are marked by vertical lines. These PIF onset times are also shown by arrows in Figs. 7a and 7b. The broken vertical lines indicate some of the minor transients that are represented by small arrows in Figs. 7a and 7b. The solar wind dawn-dusk electric field $(-\boldsymbol{V} \times \boldsymbol{B})_{Y}$, inferred from the WIND MFI and 3DP data, is superposed in Fig. 8. There is almost a one-to-one correspondence between the transients and the local maxima (minima) of $E_{Y}$ (IMF $B_{Z}$ ), particularly before 07:00 UT. While this is generally true as well for IMP-8 and GEOTAIL, these spacecraft were further away from the Sun-Earth line and closer to the bow shock. GEOTAIL was in the foreshock and the data indicate a strong presence of high frequency upstream waves. Regarding the dependence on the IMF clock angle (Fig. 7a), most of the PIFs were observed when IMF $B_{Y}$ was greater than $\left|B_{Z}\right|$, i.e. the mean IMF clock angle was $\sim 90^{\circ}$. Similar to event 1 , this is consistent with the FTE statistical results by Neudegg et al. (2000).

The PIFs were observed during a period when the electric field turned duskward and fluctuated quasi-periodically with amplitudes of $\pm 1 \mathrm{mV} / \mathrm{m}$ or more. If transmitted across the bow shock and possibly amplified in the magnetosheath, then such fluctuations are expected to modulate the reconnection rate at the subsolar magnetopause. The correlation between PIFs and positive $E_{Y}$ is similar to event 1, but this time it occurs on time scales that are an order of magnitude smaller 


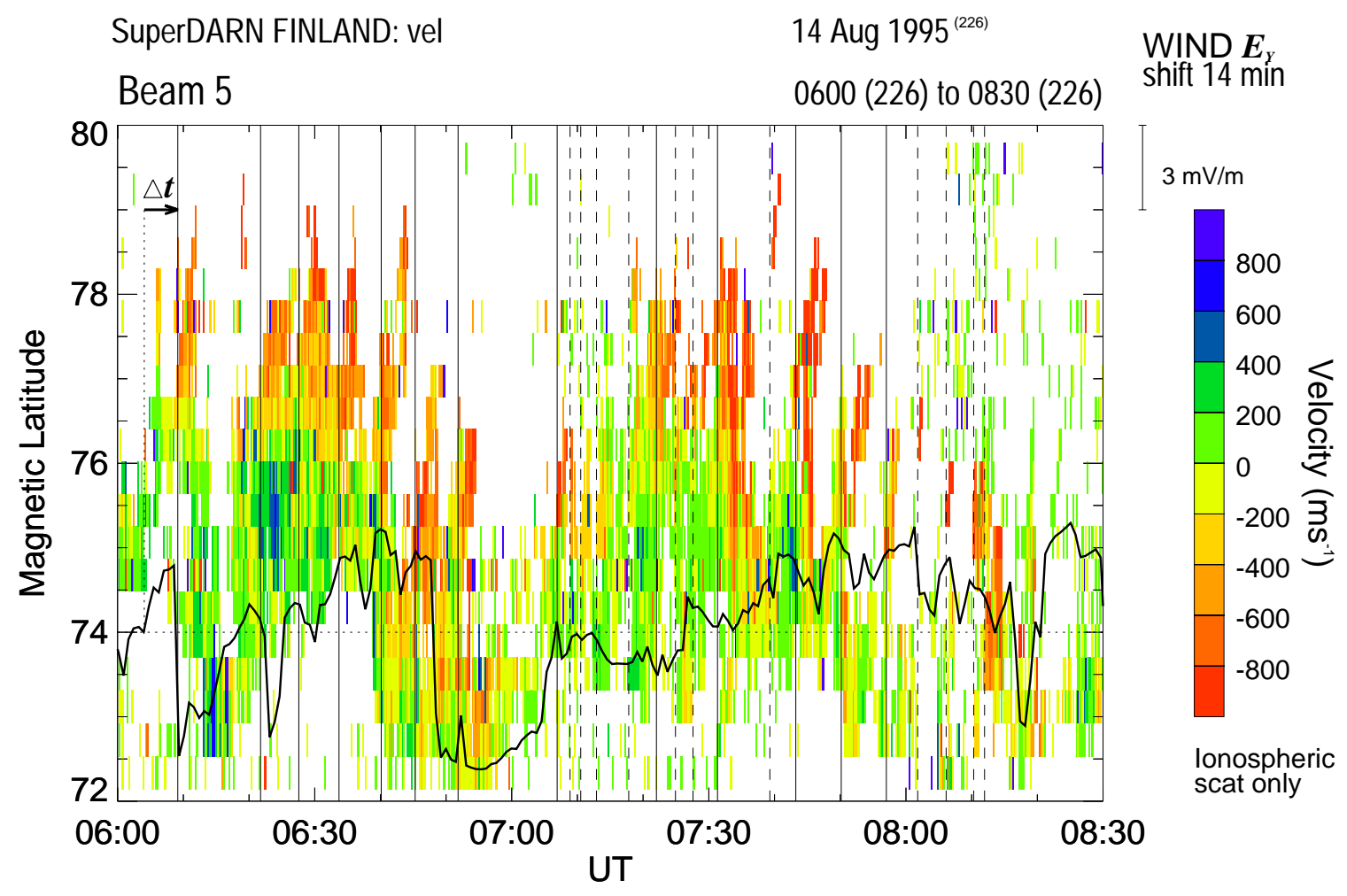

Fig. 8. Finland radar high resolution line-of-sight velocity data. The color-coded velocity (beam 5) shows quasi-periodic poleward progressing PIFs. The dawn-dusk electric field $E_{Y}$ is superposed, shifted by $14 \mathrm{~min}$. The solid/broken vertical lines show the onset times of major/minor PIFs and the horizontal arrow indicates the inferred delay $(\Delta t)$ of the reconnection onset after the IMF southward turning at the magnetopause.

than those resolved by the radar for event 1 (Fig. 5). The time shift of 14 min that is used in Fig. 8 is the time lag obtained from the cross-correlation analysis of WIND plasma data and the ground magnetometer data at NAL (Fig. 7b).

We assume that the onsets of flow transients (marked by vertical lines in Fig. 8) are ionospheric signatures of the FTE onsets at the magnetopause. The first flow transient (at 06:09 UT) occurred when the electric (magnetic) field had already turned dawnward (northward) at the magnetopause, i.e. about 5 min after the electric field $E_{Y}$ turned duskward (or the IMF $B_{Z}$ turned southward) at the magnetopause. Shorter or nearly zero delays are observed for other transients shown in Fig. 8. In general, it appears that the faster the PIF rate, the shorter the delay. Note that when $E_{Y}$ remained positive (duskward) between successive PIFs, the delay was measured from the preceding local minimum of $E_{Y}$.

\section{Discussion}

The correlations of the ground magnetic field and PIFs with the solar wind Alfvén waves suggest that on these occasions, the PIFs are driven by solar wind Alfvén waves coupling to the dayside magnetopause. The Alfvén wave dawn-dusk electric field, if imposed on the magnetopause along the $X$ line, should modulate the reconnection rate into pulses. The ionospheric and ground magnetic signatures of this coupling are consistent with FTE signatures and are associated with poleward progressing DPY currents in the cusp footprint.

Time delays between the southward (duskward) turning of the IMF (electric field) at the magnetopause and the ionospheric flow transient range from nearly zero up to several minutes. For both events presented here, there is a nearly one-to-one correspondence between the solar wind Alfvén waves (fluctuations of the IMF $B_{Z}$ and $E_{Y}$ ). The onsets of the event 2 short-period ionospheric transients (PIFs) that were observed at a rate of up to $\sim 13 \mathrm{~min}$ were delayed only up to a few minutes after the southward (duskward) turning of the IMF (electric field) at the magnetopause. In the case of event 1, the long (30-40 min) period PIFs were delayed 10-20 min after the IMF southward turning at the magnetopause. Since the Alfvén propagation time from the magnetopause to the ionosphere has already been accounted for by the difference between the observed spacecraft-toground cross-correlation lags and the estimated spacecraftto-magnetopause propagation time (the time shifts that are applied to time series are the lags derived from the crosscorrelation analysis between the spacecraft and ground magnetograms), the additional delay of the onset of the ionospheric transients remains unexplained. In another case study, Prikryl et al. (1998) inferred a relatively long ( $7 \mathrm{~min})$ time delay of PIFs after the 12 min MHD wave magnetic field turned southward in the post-noon magnetosheath near the magnetopause. We have already mentioned similar results 
by Saunders et al. (1992).

Russell et al. (1997) showed that reconnection is not immediately responsive to a southward IMF but that the FTEs can be delayed as long as $7 \mathrm{~min}$ from the arrival time of the southward IMF at the magnetopause and thus suggested this to be the intrinsic time scale that is controlled by the magnetopause or the magnetosphere rather than external drivers. In addition, they concluded that quasi-periodic FTEs can occur under steady solar wind conditions (see also Le et al., 1993). However, we note that the 17 September, 1979 solar wind data discussed by Le et al. (1993; their Fig. 2) seem to indicate Alfvénic fluctuations that we associate with the FTEs that were observed every $5-6$ min by ISEE-1 spacecraft in the magnetosheath. This can be seen more clearly by high-pass filtering the ISEE-3 IMF data while noting a steady IMF magnitude. By adopting the propagation time determined by Russell et al. (1997), there appears to be a delay of a few minutes between the expected arrival times of the southward turnings of the solar wind $B_{Z}$ component of the Alfvén wave and the FTEs observed by ISEE-1. The observed delays of PIFs support the notion of the intrinsic time scale for reconnection proposed by Russell et al. (1997), but suggest an external driver of pulsed reconnection at the dayside magnetopause.

Recently, the surface-wave induced magnetic reconnection (SWIMR) mechanism (Uberoi et al., 1996, 1999) has been invoked to explain the observed intrinsic time scale for reconnection (Russell et al., 1997). This mechanism is based on a concept of resonant absorption of Alfvén waves near a neutral point (Uberoi, 1994). It assumes a source of hydromagnetic surface waves with a broad spectrum of frequencies at the magnetopause, with the high-frequency surface waves responsible for the excitation of FLRs and the low-frequency surface waves responsible for the magnetic reconnection through resonant coupling to the collisionless tearing mode (Terasawa, 1983). Through the interaction with the bow shock that generates a set of fast, intermediate (Alfvén) and slow mode waves in the magnetosheath, solar wind Alfvén waves can provide such a source and serve as an external driver for pulsed reconnection. By the same token, it can be envisaged that FLRs (shear Alfvén waves that can couple to slow mode waves, Bhattacharjee et al., 1999), excited on the field lines adjacent to the dayside magnetopause, could provide a resonant surface on the inside neutral boundary. The boundary surface waves could provide a magnetospheric feedback to the reconnection region (Prikryl et al., 1998) by being resonantly absorbed near the neutral point (Uberoi, 1994). This notion is consistent with the Taylor model (Hahm and Kulsrud, 1985) of forced reconnection, which is a reconnection induced by perturbing the boundary of a simple slab equilibrium of an incompressible plasma with a resonant surface inside. The correspondence between the forced reconnection model and the SWIMR model has been noted by Uberoi and Zweibel (1999), who showed that "the theory of forced reconnection is actually embedded in the Alfvén resonance theory".

Applying the SWIMR theory to the magnetopause, Uberoi
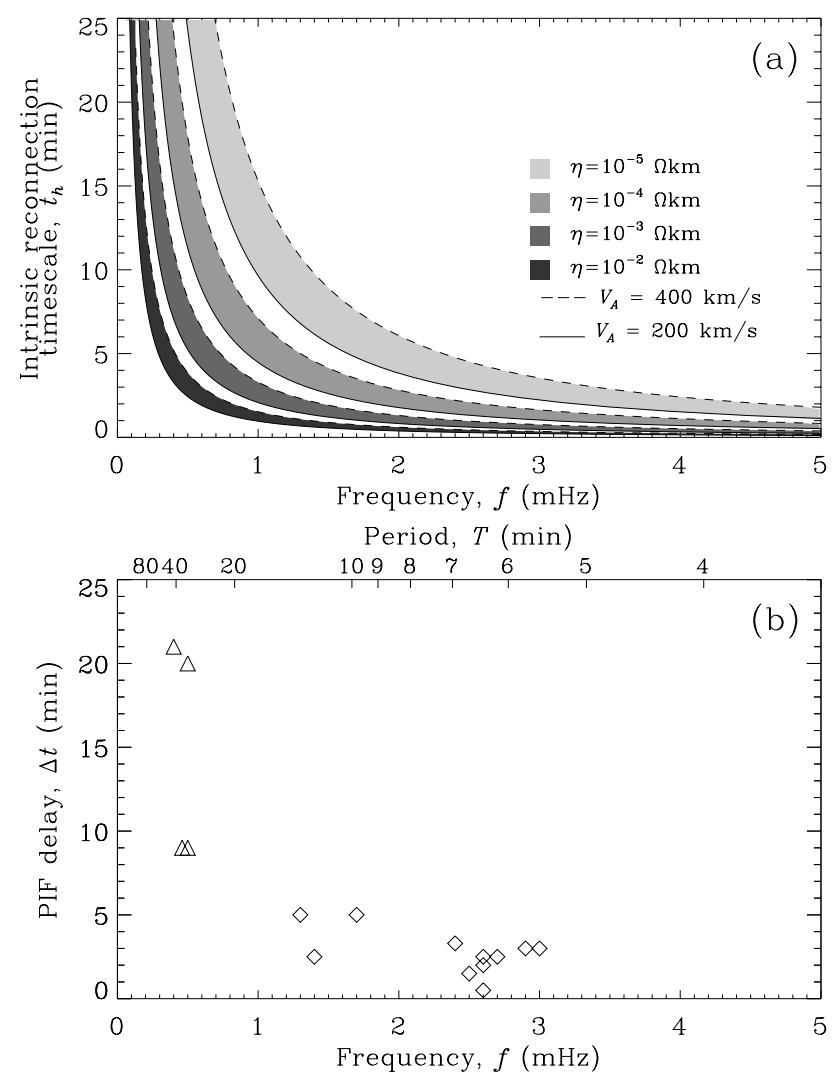

Fig. 9. (a) The intrinsic time scale for the onset of surface-wave induced magnetic reconnection (Uberoi et al., 1999) as a function of wave frequency with $k a=0.001$, and for different values of magnetic resistivity $\eta$ and Alfvén velocity $V_{A}$. (b) Observed delay of the PIF onset (ionospheric signature of reconnection onset) after the IMF southward turning at the magnetopause for several PIF events. The delays are in addition to the Alfvén propagation time between the magnetopause and the ionosphere.

et al. (1996) asked themselves a question whether near-zerofrequency surface waves with $k a \ll 1$ (where $k$ is the wave number and $a$ is the half-thickness of the neutral boundary) can exist along a boundary such as the magnetopause. They calculated the frequencies of surface waves from the symmetric surface mode dispersion relation (their Eq. 6) to be $2-20 \mathrm{mHz}$ (wave periods $1-8 \mathrm{~min}$ ) for a thin boundary ( $a=$ $100-300 \mathrm{~km}$ ), taking the Alfvén wave speed to be $300 \mathrm{~km} / \mathrm{s}$. Thus, they concluded that "near-zero-frequency and longwavelength surface waves can exist and can play an important role in the excitation of the tearing mode instability". Uberoi et al. (1999) derived an expression for the intrinsic time scale for the onset of reconnection as a function of layer thickness, magnetic resistivity and Alfvén speed. The case studies presented here support the conclusions by Uberoi et al. (1996, 1999). The PIF frequencies (periods) were $30-40 \mathrm{~min}(0.4-0.6 \mathrm{mHz})$ for event 1 , and $2-13 \mathrm{~min}(1.3-$ $8.3 \mathrm{mHz}$ ) for event 2 . Assuming that this is the range of frequencies (periods) of surface waves inducing reconnection at the magnetopause, we reverse the computation by Uberoi et 
al. (1996) and derive $a$. Using the Eqs. (5) and (11) (Uberoi et al., 1999) and $k a=0.001$, we plotted (Fig. 9a) the "intrinsic reconnection timescale $t_{H}$ " (Uberoi et al., 1999; their Fig. 1 versus frequency for the same values of Alfvén speed and magnetic viscosity, as used by the latter authors). The predicted values of $t_{H}$ increase with decreasing frequency (increasing $a$ ). For comparison, the observed delays of ionospheric flow transients (PIFs) after the IMF southward turning at the magnetopause are plotted versus PIF rate (period) in Fig. 9b. In this plot, the period for each major transient is approximated by an average of the time separations from the preceeding and succeeding transients (marked using solid vertical lines in Figs. 5 and 8). It is noted that the PIF delay time decreases with frequency similar to the intrinsic reconnection time scale (Fig. 9a).

\section{Conclusions}

Pulsed ionospheric flows (PIFs) that are believed to be ionospheric signatures of flux transfer events (FTEs) in the cusp footprint are correlated with the solar wind Alfvén waves observed by ISTP satellites. The observations of long- and short-period PIFs by the CUTLASS SuperDARN radar are supported by the IMAGE ground magnetometer data and correlated with the IMF upstream of the bow shock. Solar wind dynamic pressure variations (observed or inferred from magnetic field observations in geosynchronous orbit) indicated magnetopause surface waves. It is concluded that the dayside reconnection was pulsed by the dawn-dusk component of the Alfvén wave electric field (external driver) modulating the reconnection rate, as evidenced by the radar observations. The observed onset times of individual ionospheric transients were delayed by up to $20 \mathrm{~min}$ after the southward (duskward) turning of the IMF (electric field) at the magnetopause. This was in addition to the Alfvén propagation time from the magnetopause to the ionosphere, which is accounted for by a difference (1-15 $\mathrm{min}$ ) between the observed spacecraft-to-ground cross-correlation lag and the estimated spacecraft-to-magnetopause propagation time. The PIF delay increased with the PIF period, but appears to be small or negligible for periods of a few minutes or less. The delayed response of cusp ionosphere to the IMF southward turning supports the previous finding (Russell et al., 1997) that the reconnection at the magnetopause may not occur immediately after the southward IMF (duskward electric field) arrives at the magnetopause. The theory of resonant absorption of Alfvén surface waves near a neutral point (Uberoi, 1994; Uberoi et al., 1996; 1999) and the link between forced reconnection and Alfvén resonance theory (Uberoi and Zweibel, 1999) predicts similar time delays of the reconnection onset.

Acknowledgements. CUTLASS SuperDARN radar is supported by the Particle Physics and Astronomy Research Council (PPARC), UK, the Swedish Institute for Space Physics, Uppsala, and the Finnish Meteorological Institute, Helsinki. The IMAGE magnetometer data used in this paper were collected as a German-FinnishNorwegian-Polish project conducted by the Technical University of
Braunschweig. We benefited from discussions with G. James, D McDiarmid and D. Sibeck. D. Sibeck supplied the minimum variance analysis computer code. We acknowledge contributions by principal investigators of the ACE, GEOTAIL, IMP-8, WIND, and INTERBALL-1 instruments, namely, E. Stone (Advanced Composition Explorer), S. Kokubun (Magnetic Field Measurements), T. Mukai (Low Energy Particles), K. Tsuruda (Electric Field Measurements), A. Lazarus (Plasma Instrument), R. Lepping (Magnetic Field Investigation), R. Lin (Three-Dimensional Plasma Analyzer), and S. Romanov (Magnetic Field Investigation).

The Editor in Chief thanks C. Uberoi and another referee for their help in evaluating this paper.

\section{References}

Bhattacharjee, A., Kletzig, C. A., Ma, Z. W., Ng, C. S., Otani, N. F., and Wang, X.: Four-field model for dispersive field-line resonances: Effects of coupling between shear-Alfvén and slow modes, Geophys. Res. Lett., 26, 3281-3284, 1999.

Belcher, J. W. and Davis, Jr., L.: Large-amplitude Alfvén waves in the interplanetary medium, 2, J. Geophys. Res., 76, 3534-3563, 1971.

Berchem, J. and Russell, C. T.: Flux transfer events on the magnetopause: Spatial distribution and controlling factors, J. Geophys. Res., 89, 6689-6703, 1984.

Cable, S. and Lin, Y.: MHD simulations pf oppositely propagating Alfvén waves in the magnetosheath and solar wind, Geophys. Res. Lett., 25, 1821-1824, 1998.

Cowley, S. W. H., Freeman, M. P., Lockwood, M., and Smith, M. F.: The ionospheric signatures of flux transfer events, Eur. Space Agency Spec. Publ., ESA SP-330, 105-112, 1991

Cowley, S. W. H. and Lockwood, M.,: Excitation and decay of solar-wind driven flows in the magnetosphere-ionosphere system, Ann. Geophysicae, 10, 103-115, 1992.

Dungey, J. W.: Interplanetary magnetic field and the auroral zones, Phys. Rev. Lett., 6, 47, 1961.

Fairfield, D. H.: Averaged and unusual locations of the Earth's magnetopause and bow shock, J. Geophys. Res., 76, 6700-6716, 1971.

Goertz, C. K., Nielsen, E., Korth, A., Glassmeier, K. H., Haldoupis, C., Hoeg, P., and Hayward, D.: Observations of a possible ground signature of flux transfer events, J. Geophys. Res., 90, 4069-4078, 1985

Greenwald, R. A., Baker, K. B., Dudeney, J. R., Pinnock, M., Jones, T. B., Thomas, E. C., Villain, J.-C., Cerrisier, J.-C., Senior, C., Hanuise, C., Hunsucker, R. D., Sofko, G., Koehler, J., Nielsen, E., Pellinen, R., Walker, A. D. M., Sato, N., and Yamagishi,H.: DARN/SUPERDARN A global view of the dynamics of highlatitude convection, Space Sci. Rev., 71, 761-796, 1995.

Hahm, T. S. and Kulsrud, R. M.: Forced magnetic reconnection, Phys. Fluids, 28 (8), 2412-2418, 1985.

Hassam, A. B.: Transmission of Alfvén waves through the earth's bow shock: Theory and observation, J. Geophys. Res., 83, 643653, 1978.

King, J. H.: Availability of IMP-7 and IMP-8 data for the IMS period, in: The IMS Source Book, (Eds) Russell, C. T. and Southwood, D. J., 10-20, American Geophysical Union, 1982.

Klimov S., Romanov, S., Savin, S., Grushin, V., Nozdrachev, M., Petrukovich, A., Skalsky, A., et al.: ASPI experiment: measurements of fields and waves on board the INTERBALL-1 spacecraft, Ann. Geophysicae, 15, 514-527, 1997. 
Kokubun, S., Yamamoto, T., Acuna, M. H., Hayashi, K., Shiokawa, K., and Kawano, H.: The GEOTAIL magnetic field experiment, J. Geomag. Geoelectr., 46, 7-21, 1994.

Kuo, H., Russell, C. T., and Lee, G.: Statistical studies of flux transfer events, J. Geophys. Res., 100, 3513-3519, 1995.

Lester, M., de la Beaujardiére, O.: Foster, J. C., Freeman, M. P., Lühr, H., Ruohoniemi, J. M., and Swider, W.: The response of the large scale ionospheric convection pattern to changes in the IMF and substorms: results from the SUNDIAL 1987 campaign, Ann. Geophysicae, 11, 556-571, 1993.

Le, G., Russell, C. T., and Kuo, H.: Flux transfer events: Spontaneous or driven?, Geophys. Res. Lett., 20, 791-794, 1993.

Lin, Y., Lee, L. C., and Yan, M.: Generation of dynamic pressure pulses downstream of the bow shock by variations in the interplanetary magnetic field orientation, J. Geophys. Res., 101, 479493, 1996.

Lockwood, M. and Wild, M. N.: On the quasi-periodic nature of magnetopause flux transfer events, J. Geophys. Res., 98, 59355940, 1993.

Lockwood, M., Sandholt, P. E., Cowley, S. W. H., and Oguti, T.: Interplanetary magnetic field control of dayside auroral activity and the transfer of momentum across the dayside magnetopause, Planet. Space Sci., 67, 1347-1365, 1989.

Lockwood, M., Denig, W. F., Farmer, A. D., Davda, V. N., Cowley, S. W. H., and Lühr, H.: Ionospheric signatures of pulsed reconnection at the Earth's magnetopause, Nature, 361, 424-428, 1993.

McKenzie, J. F. and Westphal, K. O.: Transmission of Alfvén waves through the earth's bow shock, Planet. Space Sci., 17, 10291037, 1969.

McKenzie, J. F. and Westphal, K. O.: Interaction of hydromagnetic waves with hydromagnetic shocks, Phys. Fluids., 13, 630-640, 1970.

McWilliams, K. A., Yeoman, T. K., and Provan, G.: A statistical survey of dayside pulsed ionospheric flows as seen by the CUTLASS Finland HF radar, Ann. Geophysicae, 18, 445-453, 2000.

Milan, S. E., Lester, M., Cowley, S. W. H., and Brittnacher, M.: Convection and auroral response to a southward turning of the IMF: Polar UVI, CUTLASS, and IMAGE signatures of transient magnetic flux transfer at the magnetopause, J. Geophys. Res., 105, 15 741-15 755, 2000.

Mukai, T., Machida, S., Saito, Y., Hirahara, M., Terasawa, T., Kaya, N., Obara, T., Ejiri, M., and Nishida, A.: The Low Energy Particle (LEP) Experiment onboard the GEOTAIL satellite, J. Geomag. Geoelectr., 46, 669-692, 1994.

Neudegg, D. A., Cowley, S. W. H., Milan, S. E., Yeoman, T. K., Lester, M., Provan, G., Haerendel, G., Baumjohann, W., Nikutowski, B., Büchner, J., Auster, U., Fornacon, K.-H., and Georgescu, E.: A survey of magnetopause FTEs and associated flow bursts in the polar ionosphere, Ann. Geophysicae, 18, 416435,2000

Nishitani, N., Ogawa, T., Pinnock, M., Freeman, M. P., Dudeney, J. R., Villain, J.-P., Baker, K. B., Sato, N., Yamagishi, H., and Matsumoto, H.: A very large scale flow burst observed by the SuperDARN radars, J. Geophys. Res., 104, 22 469-22 486, 1999.

Ogilvie, K. W. and Parks, G. K.: First results from WIND spacecraft, Geophys. Res. Lett., 23, 1179-1181, 1996.

Øieroset, M., Sandholt, P. E., Lühr, H., Denig, W. F., and Moretto, T.: Auroral and geomagnetic events at cusp/mantle latitudes in the prenoon sector during positive IMF $B_{y}$ conditions:Signatures of pulsed magnetopause reconnection, J. Geophys. Res., 102, 7191-7205, 1997.
Paschmann, G., Sonnerup, B. U.Ö., Papamastorakis, I., Sckopke, N., Haerendel, G., Bame, S. J., Asbridge, J. R., Gosling, J. T., Russel, C. T., and Elphic, R. C.: Plasma acceleration at the Earth's magnetopause: Evidence for reconnection, Nature, 282, 243, 1979.

Pinnock, M., Rodger, A. S., Dudeney, J. R., Rich, F., and Baker, K. B.: High spatial and temporal resolution observations of the ionospheric cusp, Ann. Geophysicae, 13, 919-925, 1995.

Prikryl, P., Greenwald, R. A., Sofko, G. J., Villain, J. P., and Ziesolleck, C. W. S., and Friis-Christensen, E.: Solar-wind driven pulsed magnetic reconnection at the dayside magnetopause, Pc5 compressional oscillations, and field line resonances, J. Geophys. Res., 103, 17 307-17322, 1998.

Prikryl, P., MacDougall, J. W., Grant, I. F., Steele, D. P., Sofko, G. J., and Greenwald, R. A.: Observations of polar patches generated by solar wind Alfvén wave coupling to the dayside magnetosphere, Ann. Geophysicae, 17, 463-489, 1999.

Provan, G., Yeoman, T. K., and Milan, S. E.: CUTLASS Finland radar observations of the ionospheric signatures of flux transfer events and the resulting plasma flows, Ann. Geophysicae, 16, 1411-1422, 1998.

Provan, G. and Yeoman, T. K.: Statistical observations of the MLT, latitude and size of pulsed ionospheric flows with the CUTLASS Finland radar, Ann. Geophysicae, 17, 855-867 1999.

Richardson, J. D. and Paularena, K. I.: The orientation of plasma structure in the solar wind, Geophys. Res. Lett., 25, 2097-2100, 1998.

Rijnbeek, R. P., Cowley, S. W. H., Southwood, D. J., and Russell, C. T.: A survey of dayside flux transfer events observed by ISEE 1 and 2, J. Geophys. Res., 89, 786-800, 1984.

Roelof, E. C. and Sibeck, D. G.: Magnetopause shape as a bivariate function of interplanetary magnetic field $B_{z}$ and solar wind dynamic pressure, J. Geophys. Res., 98, 21 421-21 450, 1993.

Russell, C. T.: The configuration of the magnetosphere, in: Critical Problems of Magnetospheric Physics, (Ed) Dyer, E. R., NSF, Washington, D. C., 1972.

Russell, C. T. and McPherron, R. L.: The magnetotail and substorms, Space Sci. Rev., 15, 205, 1973.

Russell, C. T. and Elphic, R. C.: Initial ISEE magnetometer results: Magnetopause observations, Space Sci. Rev., 22, 681-715, 1978.

Russell, C. T. and Elphic, R. C.: ISEE observations of flux transfer events at the dayside magnetopause, Geophys. Res. Lett., 6, 33, 1979.

Russell, C. T., Le, G., Kawano, H., Petrinec, S. M., and Zhang, T. L.: Intrinsic time scale for reconnection on the dayside magnetopause, Adv. Space Res., 19, 1913-1917, 1997.

Russell, C. T., Wang, Y. L., Raeder, J., Tokar, R. T., Smith, C. W., Ogilvie, K. W., Lazarus, A. J., Lepping, R. P., Szabo, A., Kawano, H., Mukai, T., Savin, S., Yermolaev, Y. I., Zhou, X.Y., and Tsurutani, B. T.: J. Geophys. Res., 105, 25 143-25 154, 2000.

Sandholt, P. E., Lockwood, M., Oguti, T., Cowley, S. W. H., Freeman, K. S. C., Lebekk, B., Egeland, A., and Willis, D. M.: Midday auroral breakup events and related energy and momentum transfer from the magnetosheath, J. Geophys. Res., 95, 10391060, 1990.

Saunders, M. A., Freeman, M. P., Southwood, D. J., Cowley, S. W. H., Lockwood, M., Samson, J. C., Farrugia, C. J., and Hughes, T. J.: Dayside ionospheric convection changes in response to longperiod interplanetary magnetic field oscillations: Determination of the ionospheric phase velocity, J. Geophys. Res., 97, 1937319380, 1992. 
Sibeck, D. G., Takahashi, K., Kokubun, S., Mukai, T., Ogilvie, K. W., and Szabo, A.: A case study of oppositely propagating Alfvénic fluctuations in the solar wind and magnetosheath, Geophys. Res. Lett., 24, 3133-3136, 1997.

Sibeck, D. G., Phan, T.-D., Lin, R. P., Lepping, R. P., Mukai, T., and Kokubun, S.: A survey of MHD waves in the magnetosheath: International Solar Terrestrial Program observations, J. Geophys. Res., 105, 129-137, 2000.

Siscoe, G. L., Davies, Jr., L., Coleman, Jr., P. J., Smith, E. J., and Jones, D. E.: Power spectra and discontinuities of the interplanetary magnetic field: Mariner 4, J. Geophys. Res., 73, 61-82, 1968.

Smith, C. W., Acuna, M. H., Burlaga, L. F., L'Heureux, J., Ness, N. F., and Scheifele, J.: The ACE Magnetic Field Experiment, Space Science Reviews, 86, 613-632, 1999.

Sonnerup, B. U. Ø. and Cahill, Jr., L. J.: Magnetopause structure and attitude from Explorer 12 observations, J. Geophys. Res., 72, 171-183, 1967.

Spreiter, J. R. and Stahara, S. S.: A new predictive model for determining solar wind-terrestrial planet interaction, J. Geophys. Res., 85, 6769-6777, 1980.

Stauning, P., Clauer, C. R., Rosenberg, T. J., Friis-Christensen, E., and Sitar, R.: Observations of solar-wind-driven progression of interplanetary magnetic field $B_{y}$-related dayside ionospheric disturbances, J. Geophys. Res., 100, 7567-7585, 1995.

Terasawa, T.: Hall current effect on tearing mode instability, Geophys. Res. Lett., 10, 475, 1983.

Tsuruda, K., Hayakawa, H., Nakamura, M., Okada, T., Matsuoka, A., Mozer, F. S., and Schmidt, R.: Electric field measurement on the GEOTAIL satellite, J. Geomag. Geoelectr., 40, 693-711, 1994.

Tsurutani, B. T. and Gonzalez, W. D.: The cause of high intensity long-duration continuous AE activity (HILDCAAs): Interplanetary Alfvén wave trains, Planet. Space Sci., 35, 405, 1987.

Tu, C.-Y. and Marsch, E.: MHD structures, waves and turbulence in the solar wind: Observations and theories, Space Sci. Rev., 73, 1-210, 1995.

Uberoi, C.: Resonant absorption of Alfvén waves near a neutral point, J. Plasma Phys., 52, 215-221, 1994.

Uberoi, C., Lanzerotti, L. J., and Wolfe, A.: Surface waves and magnetic reconnection at a magnetopause, J. Geophys. Res., 101, 24 979-24 983, 1996.

Uberoi, C., Lanzerotti, L. J., and Maclennan, C. G.: Remarks on the intrinsic timescale for reconnection on the dayside magnetopause, J. Geophys. Res., 104, 25 153-25 157, 1999.

Uberoi, C. and Zweibel, E. G.: Alfvén resonances and forced reconnection, J. Plasma Phys., 62 (3), 345-350, 1999.

Van Eyken, A. P., Rishbeth, H., Willis, D. M., and Cowley, S. W. H.: Initial EISCAT observations of plasma convection at invariant latitudes $70^{\circ}-77^{\circ}$, J. Atmos. Terr. Phys., 46, 635-641, 1984.

Viljanen, A. and Häkkinen, L.: IMAGE magnetometer network, in Satellite-ground based coordination sourcebook, (Eds) Lockwood, M., Wild M. N., and Opgenoorth, H. J., ESA publications SP-1198, 111-117, 1997.

Vorobjev, V. G., Gustafsson, G., Starkov, G. V., Feldstein, Y. I., and Shevnina, N. F.: Dynamics of day and night aurora during substorms, Planet. Space Sci., 23, 269-278, 1975. 